\title{
Antimicrobial and cytotoxic activities of marine sponge-derived fungal extracts isolated from Dactylospongia sp.
}

\author{
Neny Sandrawati ${ }^{1,2}$, Shuci Permata Hati ${ }^{2}$, Fujia Yunita ${ }^{2}$, Andani Eka Putra ${ }^{1}$, Friardi Ismed ${ }^{2}$,Trina Ekawati Tallei ${ }^{3}$, \\ Triana Hertiani ${ }^{4}$, Dian Handayani ${ }^{*}$ \\ ${ }^{1}$ Department of Biomedical, Faculty of Medicine, Andalas University, 25163 Padang, Indonesia. \\ ${ }^{2}$ Laboratory of Sumatran Biota / Faculty of Pharmacy, Andalas University, Kampus Limau Manis, 25163 Padang, Indonesia. \\ ${ }^{3}$ Department of Biology, Faculty of Mathematics and Natural Sciences, Sam Ratulangi University, Kampus UNSRAT Kleak, 95115 Manado, Indonesia. \\ ${ }^{4}$ Faculty of Pharmacy, Gadjah Mada University, Sekip Utara, Yogyakarta, Indonesia.
}

\section{ARTICLE INFO \\ Received on: 29/10/2019 \\ Accepted on: 30/01/2020 \\ Available online: 04/04/2020}

\section{Key words:}

Marine sponge,

Dactylospongia sp., marine-derived fungi, antibacterial activity, cytotoxic activity, methicillin-resistant Staphylococcus aureus (MRSA), multidrug-resistant Pseudomonas aeruginosa (MDRPA).

\begin{abstract}
This study is the first report on the antimicrobial and cytotoxic activities of fungal extracts isolated from marine sponge Dactylospongia sp., which is collected from Mandeh Island, West Sumatra, Indonesia. The isolation of fungal was conducted using dilution method with Sabouraud Dextrose Agar + chloramphenicol $(0.05 \%)$ as a medium. The pure isolated fungal was cultivated on rice medium at temperature $25^{\circ} \mathrm{C}-27^{\circ} \mathrm{C}$ and then extracted using ethyl acetate solvent. The ethyl acetate extract of each isolated fungal was tested for antimicrobial and cytotoxic activities. Nine fungal strains have been isolated from this sponge. Two ethyl acetate extracts of fungal strains (Dc03 and Dc04) were categorized as having strong inhibition against the growth of Staphylococcus aureus, Escherichia coli, methicillinresistant $S$. aureus, and multidrug-resistant Pseudomonas aeruginosa in a concentration of 5\% with zone inhibition in range of $12.31 \pm 0.54-16.14 \pm 0.75 \mathrm{~mm}$. The cytotoxic activity screening of the ethyl acetate extracts of fungal strains was done by using the brine shrimp lethality test. Four fungal strains had $\mathrm{LC}_{50}$ below $80 \mu \mathrm{g} / \mathrm{ml}(\mathrm{Dc} 03$, Dc04, Dc05, and Dc08) and were further tested with MTT (3-[4,5-dimethylthiazol-2-yl]-2,5 diphenyl tetrazolium bromide) assay on T47D cell line. These selected fungi were identified molecularly as Cladosporium halotolerans MN859971, Penicillium citrinum MN859968, Aspergillus versicolor MN859970, and Aspergillus sydowii MN859969, respectively. The results suggest that these fungal strains are quite rich in the production of bioactive compounds that are very effective as antibacterial and cytotoxic agents.
\end{abstract}

\section{INTRODUCTION}

Marine-derived fungi have attracted much attention in recent years due to the production of structurally unique pharmacological properties (Blunt et al., 2007; 2015). Fungi have proven as promising sources of new compounds compared to other microbial sources such as bacterial isolates from the sea (Gamal-Eldeen et al., 2009). The first report of bioactive compounds from marine-derived fungi was cephalosporin $\mathrm{C}$,

"Corresponding Author

Dian Handayani, Laboratory of Sumatran Biota / Faculty of Pharmacy, Andalas University, Kampus Limau Manis, 25163 Padang, Indonesia.

E-mail:dianhandayani@phar.unand.ac.id which was isolated from Acremonium chrysogenum that associated with a sewage outlet in the Mediterranean Sea close to the Sardinia Island. Next, cephalosporin $\mathrm{C}$ was developed as a lead compound of modern cephalosporin antibiotics for the treatment of numerous infections (Abraham and Loder, 1972).

Many researchers, nowadays, have developed the study which is focused on the biological activity of marine-derived compounds. Screening for antimicrobial and cytotoxic activity of marine-derived compounds is becoming more popular due to the search for novel antibiotic and antitumor agents. Hu et al. (2015) reported, in their study, that of 4,196 biologically active compounds isolated fungi from a marine organism, 2,225 had anticancer activities (56\%) and 521 had antibacterial activities (13\%).

Some symbiotic fungi of marine sponge in West Sumatra, Indonesia, had been reported to produce bioactive 
compounds with various biological activities. Fungi associated with marine sponge Haliclona fascigera were reported active toward pathogenic bacteria such as Staphylococcus aureus and Candida albicans (Handayani et al., 2015a; 2015b). Marine sponge Acanthrongylophora ingens and Neopetrosia chaliniformis AR-01-derived fungi collected from Mandeh Island, West Sumatra, Indonesia, showed an inhibitory activity against Bacillus subtilis, Staphylococcus epidermidis, Salmonella typhi, and Escherichia coli. The screening for cytotoxic activity using brine shrimp lethality test (BSLT) method against brine shrimp larvae also showed a significant $\mathrm{LC}_{50}$ value (Handayani and Aminah, 2017a; Handayani and Artasasta, 2017b).

In the study of marine-derived microbial in West Sumatra, Indonesia, we had reported the potential marine sponge-derived bacteria (Handayani et al.,2015a; 2015b; 2016; Sandrawati et al., 2019), marine sponge-derived fungi (Handayani et al., 2018a; 2018b; 2019b), and algae-derived fungi (Handayani et al., 2019a) which displayed interesting biological activities. In this present study, we described the isolation of fungi associated with marine sponge Dactylospongia sp. which was cultivated on a rice medium. We also evaluate the antimicrobial and cytotoxic activities of its EtOAc extracts and the identification of fungi by microscopic and molecular determination.

\section{MATERIALS AND METHODS}

\section{Sample material}

Sponge sample code DH3 was collected from the Mandeh Island, West Sumatra, in a depth of $\pm 10 \mathrm{~m}$. It was surface sterilized by sterile seawater three times and stored in a plastic bag. The sample was placed in an icebox and transferred to the laboratory immediately for the isolation of symbiotic fungi.

\section{Identification of sponge}

Sponge identification was conducted by Dr. Nicole J. De Voogd at the Natural Biodiversity Center, the Netherland. The sponge code DH3 was identified as Dactylospongia sp.

\section{Isolation, cultivation, and extraction of symbiotic fungi}

The method of isolation and cultivation of symbiotic fungi was carried out in the previous research (Kjer et al., 2010). The symbiotic fungi were macerated with ethyl acetate in the ratio 1:1 with three repetitions. The resulting extract was then evaporated in vacuo with a rotary evaporator and used for the antimicrobial and cytotoxic assays.

\section{Screening for antimicrobial activity}

The EtOAc extract of fungus was tested using pathogenic microbial as follows: S. aureus ATCC25923, E. coli ATCC25922, C. albicans, and clinical isolate methicillin-resistant Staphylococcus aureus (MRSA) which were obtained from Cipto Mangunkusumo Hospital, Jakarta, Indonesia, and multidrugresistant Pseudomonas aeruginosa (MDRPA) was from M. Djamil Hospital, West Sumatera, Indonesia.

\section{DISK DIFFUSION METHOD}

The EtOAc extract of fungus was prepared for the concentration of 1,3 , and $5 \mathrm{mg} / \mathrm{ml}$ in dimethyl sulfoxide (DMSO) solvent. About $10 \mu \mathrm{l}$ of each EtOAc extract was pipetted onto a 6-mm sterile paper disk (Advantec $\left.{ }^{\circledR}\right)$. Each of the disk was put on the surface of the Sabouraud Dextrose Agar $\left(\right.$ Merck $\left.^{\circledR}\right)$ medium containing $0.7 \mathrm{McF}$ arland of fungi suspension and on the surface of Natrium Agar $\left(\right.$ Merck $\left.^{\circledR}\right)$ contained 0.5 McFarland of bacterial suspension. Chloramphenicol $\left(\right.$ Oxoid $^{\circledR}$ ) in a concentration of 30 $\mu \mathrm{g} / \mathrm{ml}$ was used as a positive control for antibacteria and nystatin $\left(\mathrm{Oxoid}^{\circledR}\right)$ in a concentration of 100 unit/disk as antifungi. The paper disk was also inoculated with $100 \mu \mathrm{DMSO}$ as a negative control. Each treatment consisted of three replicates.

The plates were incubated overnight at $37^{\circ} \mathrm{C}$ for bacteria and at $25^{\circ} \mathrm{C}-27^{\circ} \mathrm{C}$ for fungi. The antimicrobial screening was conducted based on the method described previously (Handayani et al., 2015a; 2017a; 2017b; 2018a; 2018b). The clear zones in the media were an indication of antimicrobial activities. The diameter of the inhibition zones was measured, and the standard deviations were also determined. The strain that showed inhibition zone $>10 \mathrm{~mm}$ was selected for phytochemical test, microscopic examination, and molecular identification.

\section{Screening for Toxicity and cytotoxic activity}

A preliminary study for toxicity activity was conducted with the BSLT method which as written in the previous research report (Handayani et al., 2018a; 2018b; Meyer et al., 1982). The present cytotoxic assay was performed by MTT assay using T47D (human ductal breast epithelial tumor) cell lines using four potential fungi. Fungal extracts were made in various concentrations of $1,000,500,250,125,62.5$, and $31.25 \mathrm{ppm}$. Value Ln concentration is regressed against cell viability. Regression equations were then used to calculate the $\mathrm{IC}_{50}$ value.

\section{Phytochemical test}

The phytochemical examination was carried out for the EtOAc extract of symbiotic fungi that had the clear zone $>10 \mathrm{~mm}$ as the standard methods described previously (Handayani et al., 2019a; 2019b; Tiwari et al., 2011).

\section{Microscopic examination}

The potential fungi with cytotoxic activity were examined under a microscope with a magnification of $\times 2000$. The specimen was put on object glass and dripped with lactophenol and mixed. The specimen was covered with cover glass. The morphology of the specimen was observed, and the result was compared with literature.

\section{Molecular identification}

The procedure for DNA extraction was performed according to the modification method of Atashpaz et al. (2010). Four endophytic fungal strains with the highest antimicrobial and cytotoxic activities were identified using the internal transcribed spacer (ITS) region. The Polymerase Chain Reaction ( PCR) reaction contained KOD FX Neo (Toyobo, Tokyo, Japan) with ITS1 and ITS4 primers, and the amplification was carried out using the method described by Ferrer et al. (2001).

The PCR products were sent to the first BASE, Malaysia, for sequencing. The sequences were subjected to pairwise sequence alignment using the BLAST (Basic Local Alignment Search Tool) program on NCBI( National Center for Biotechnology Information) and MycoBank database. The phylogenetic tree was constructed using the neighbor-joining 
method, and p-distance model was set with a bootstrap value of 1,000 replication integrated into MEGA 7.0 software (Kumar et al., 2016).

\section{RESULTS AND DISCUSSION}

Nine fungal isolates (designated as Dc01 to Dc09) from sponge Dactylospongia sp. were able to be isolated. The ethyl acetate extract of each fungal isolates was tested for antimicrobial activities. Four fungal isolates showed good antibacterial activity in various concentrations against $S$. aureus and E. coli (Table 1). Davis and Stout (1971) classified the strength of inhibition into four categories based on the diameter of inhibition as follows: very strong ( $\geq 20 \mathrm{~mm})$, strong $(10-20 \mathrm{~mm})$, medium $(5-10 \mathrm{~mm})$, and weak $(\leq 5 \mathrm{~mm})$. The fungal extracts of Dc03, Dc04, and Dc08 in the concentration of $5 \%$ showed strong inhibition against $S$. aureus and E. coli. The isolates Dc03 and Dc04 were selected for further test against resistant bacteria. The isolate Dc04 showed the biggest inhibition zone for MRSA with a diameter of $15.50 \pm$ $0.54 \mathrm{~mm}$. The potential fungi were next subjected to determine the phytochemical constituents and identification of species.

Cytotoxic activity screening results are listed in Fig. 1. If the $\mathrm{LC}_{50}$ value is below $1,000 \mu \mathrm{g} / \mathrm{ml}$, then the sample is classified as toxic, and if it is greater than $1,000 \mu \mathrm{g} / \mathrm{ml}$, it is classified as nontoxic (Meyer et al., 1982). In this present study, all fungal extracts were toxic and, therefore, have the potential to produce cytotoxic compounds. The five fungal isolates with $\mathrm{LC}_{50}$ value below $80 \mu \mathrm{g} / \mathrm{ml}$ were selected further to determine their active compounds and species identification.

Further testing on the cytotoxic activity was conducted by MTT assay using the T47D cell lines. The first step was the determination of the viability percentage of cancer cells in the culture medium after the addition of fungal extracts with a concentration of $100 \mu \mathrm{g} / \mathrm{ml}$. Data obtained were analyzed by a linear regression equation to obtain $\mathrm{IC}_{50}$ value. The $\mathrm{IC}_{50}$ extract value of Dc03, Dc04, Dc05, and Dc08 against T47D cell line difference was in the range of 225.75-1,760.98 ppm (Table 2). The potential fungal extracts did not show good $\mathrm{IC}_{50}$ value. It might be due to the cytotoxic activity of fungal extracts selective to another human cancer cell lines.

The results of the screening of antimicrobial and cytotoxic activity showed that the isolates such as Dc03, Dc04, Dc05, and Dc08 had a high potential as antibacterial and cytotoxic agents. The chemical constituent analysis showed that most of the fungal extracts contained terpenoid, steroid, and flavonoid but did not contain alkaloid, phenol, and saponin (Table 3 ).

The morphological observations showed that isolate Dc03 was greenish-brown, the surface was centered to the middle, and the bottom was black with white flat edges (Fig. 2). The microscopic identification showed that this fungus had round conidia bulkhead along the conidiophores (Fig. 2). The examination of macroscopic and microscopic observation was concordance with literature that Dc03 was identified as Cladosporium halotolerans MN859971. This result was confirmed by molecular identification conducted at Indonesian Center for Biodiversity and Biotechnology. A BLAST search in NCBI-GenBank and MycoBank showed that isolate Dc03 had $100 \%$ identity with $C$. halotolerans MN859971. The phylogenetic tree showed that Dc03 was clustered together with $C$. halotolerans strain DTO127E8 (Fig. 3). The study about secondary metabolites from C. halotolerans is still limited. Pang et al. (2017) reported that Cladosporisteroid A, B, and C and Cerevisterol compounds isolated from Cladosporium $\mathrm{sp}$. which was derived from marine sponge Callyspongia sp. showed antiviral and cytotoxic activities (Pang et al., 2017).

The fungus Dc04 strain was brownish-green, the surface was stripped to the center, and the bottom was yellow-white and white flat edges (Fig. 2). In the microscopic observation, Dc04 had conidiophores that are not broad but branched, phialide, and with round conidia (Fig. 2). The isolate Dc04 was identified molecularly as Penicillium citrinum MN859968. On the phylogenetic tree, the isolate Dc04 resided in the same with P. citrinum strain ercha 16 (Fig. 3). The secondary metabolites isolated from the marinederived fungi from the genus Penicillium produced various bioactive compounds with wide biological activities, such as

Table 1. Antimicrobial activity of EtOAc extracts of marine-derived fungi from Dactylospongia sp.

\begin{tabular}{|c|c|c|c|c|c|c|c|c|c|c|c|}
\hline \multirow{3}{*}{ Fungi code } & \multicolumn{11}{|c|}{ Zone of inhibition $(\mathrm{mm}) \pm$ standard deviation $(\mathrm{SD})$} \\
\hline & \multicolumn{3}{|c|}{ E. coli } & \multicolumn{3}{|c|}{ S. aureus } & \multicolumn{3}{|c|}{ C. albicans } & \multirow{2}{*}{$\begin{array}{c}\text { MRSA } \\
5 \%\end{array}$} & \multirow{2}{*}{$\begin{array}{c}\text { MDRPA } \\
5 \%\end{array}$} \\
\hline & $5 \%$ & $3 \%$ & $1 \%$ & $5 \%$ & $3 \%$ & $1 \%$ & $5 \%$ & $3 \%$ & $1 \%$ & & \\
\hline Dc01 & $8.51 \pm 0.40$ & $6.43 \pm 0.05$ & - & - & - & - & - & - & - & $\mathrm{n}$ & $\mathrm{n}$ \\
\hline Dc02 & - & - & - & - & - & - & - & - & - & $\mathrm{n}$ & $\mathrm{n}$ \\
\hline De03 & $12.74 \pm 0.45$ & $11.28 \pm 0.10$ & $9.56 \pm 0.36$ & $11.84 \pm 0.10$ & $11.28 \pm 0.10$ & $9.39 \pm 0.14$ & - & - & - & $10.88 \pm 1.25$ & $9.42 \pm 1.59$ \\
\hline Dc04 & $15.50 \pm 0.30$ & $14.21 \pm 0.25$ & $11.08 \pm 0.30$ & $16.14 \pm 0.75$ & $12.75 \pm 0.27$ & $10.30 \pm 0.24$ & - & - & - & $15.50 \pm 0.54$ & $8.33 \pm 0.29$ \\
\hline Dc05 & $10.41 \pm 0.42$ & $8.01 \pm 0.43$ & $6.21 \pm 0.14$ & $6.37 \pm 0.42$ & - & - & - & - & - & $\mathrm{n}$ & $\mathrm{n}$ \\
\hline Dc06 & $6.53 \pm 0.39$ & - & - & - & - & - & - & - & - & $\mathrm{n}$ & $\mathrm{n}$ \\
\hline Dc07 & $6.50 \pm 0.23$ & - & - & $8.70 \pm 0.35$ & $6.42 \pm 0.28$ & - & - & - & - & $\mathrm{n}$ & $\mathrm{n}$ \\
\hline De08 & $12.31 \pm 0.54$ & $10.55 \pm 0.40$ & $7.53 \pm 0.29$ & $14.25 \pm 0.10$ & $9.46 \pm 0.29$ & $7.19 \pm 0.13$ & - & - & - & $\mathrm{n}$ & $\mathrm{n}$ \\
\hline De09 & $6.15 \pm 0.11$ & - & - & $8.61 \pm 0.21$ & $7.10 \pm 0.05$ & - & - & - & - & $\mathrm{n}$ & $\mathrm{n}$ \\
\hline $\begin{array}{l}\text { Positive } \\
\text { control }\end{array}$ & & 22.15 & & & 22.35 & & & 22.15 & & 24 & 8.75 \\
\hline $\begin{array}{l}\text { Negative } \\
\text { control }\end{array}$ & & - & & & - & & & - & & - & - \\
\hline
\end{tabular}




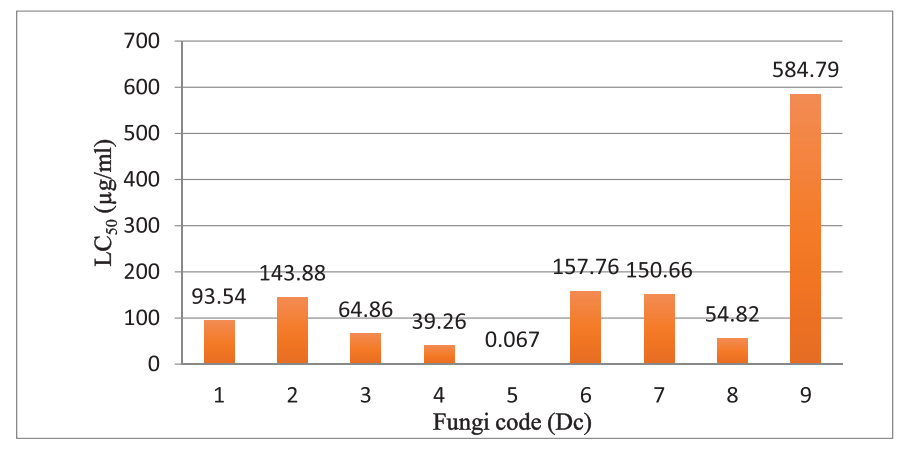

Figure 1. The cytotoxic activity of EtOAc extracts of marine-derived fungi from Dactylospongia sp.

Table 2. The $\mathrm{IC}_{50}$ value of selected fungal extracts on T47D cancer cell line.

\begin{tabular}{clc}
\hline No. & Code of Extract & ${\text { The } \mathbf{I C}_{\mathbf{5 0}} \text { value of T47D cell line }(\mathbf{p p m})}$ \\
\hline 1 & Dc03 & 225.75 \\
2 & $\mathrm{Dc04}$ & 640.12 \\
3 & $\mathrm{Dc} 05$ & $1,760.98$ \\
4 & $\mathrm{Dc} 08$ & 456.75 \\
5 & Doxorubicin & 10.05 \\
\hline
\end{tabular}

Table 3. The chemical constituents of EtOAc extracts of marine-derived fungi from Dactylospongia sp.

\begin{tabular}{lcccccc}
\hline \multirow{2}{*}{ Fungi code } & \multicolumn{7}{c}{ Chemical constituents } \\
\cline { 2 - 7 } & Alkaloid & Flavonoid & Terpenoid & Steroid & Phenolic & Saponin \\
\hline Dc01 & - & - & - & + & - & - \\
Dc03 & - & + & - & + & - & - \\
Dc04 & - & + & + & - & - & - \\
Dc05 & - & - & + & + & - & - \\
Dc08 & - & - & + & + & - & - \\
\hline
\end{tabular}

Note: - = no reaction

antifouling polyketides (Bao et al., 2013), antibacterial communal A (Wang et al., 2012), cytotoxic penicinoline (Shao et al., 2010), and many others. Some bioactive compounds from P. citrinum that had been reported included citrinin (Subramani et al., 2013), isocyclocitrinol A and 22-acetylisocyclocitrinol A (Amagata et al., 2003), and $\gamma$-sitosterol, stigmasterol, pentadecanoic acid, and 14-methyl-methyl ester-17-Pentatriacontene (Binh et al., 2018). The genera of Penicillium are not only marine borne but also soil borne as well. Even though their terrestrial counterparts have been the subject of chemical screening for at least five decades, marine-derived Penicillium sp. continues to yield a broad of new secondary metabolites.

The next potential fungi were Dc05 which had yellowish-green, hairy surface, white, and flat edges' colony (Fig. 2). Dc05 had round conidia, conidiophores, phialide, and vesicles (Fig. 2). The macroscopic and microscopic determination allowed Dc05 as Aspergillus versicolor MN859970. Molecular identification showed that Dc05 had an identity $100 \%$ with $A$. versicolor strain upm1 on BLAST analysis (Fig. 3). The isolate $\mathrm{Dc} 05$ had the highest cytotoxic activity with the $\mathrm{LC}_{50}$ value of $0.067 \mu \mathrm{g} / \mathrm{ml}$. Many secondary metabolites have been isolated from $A$. versicolor with various biological activities, such as

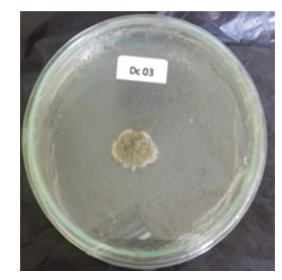

A1

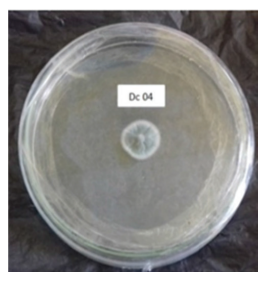

B1

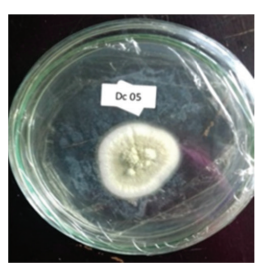

C1

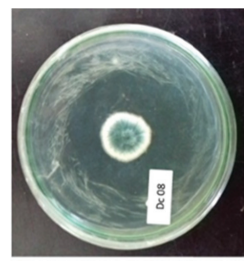

D1

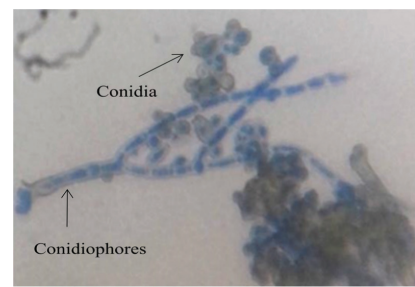

A2

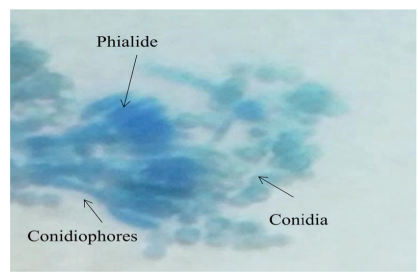

B2

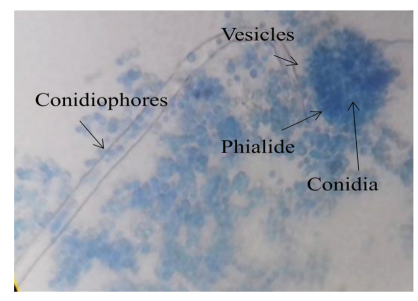

$\mathrm{C} 2$

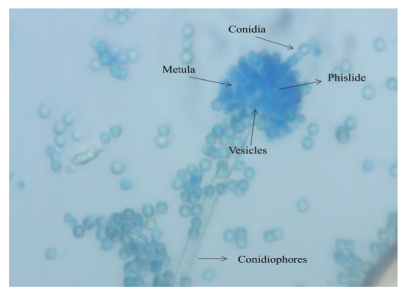

D2
Figure 2. The macroscopic (left side) and microscopic (right side) observations of the fungi. A1 and A2 are the isolate Dc03 (C. halotolerans MN859971), $\mathrm{B} 1$ and $\mathrm{B} 2$ are the isolate Dc04 (P. citrinum MN859968), $\mathrm{C} 1$ and $\mathrm{C} 3$ are the isolate Dc05 (A. versicolor MN859970), and D1 and D2 are the isolate Dc08 ( $A$. sydowii MN859969).

5 -methoxydihydrosterigmatocystin as antimicrobial agent (Song et al., 2014), aspergoterpenins A-B with antimicrobial and cytotoxic activity (Guo et al., 2018), 1'-O-ethyl-6,8-di-O-methylaverantin as antibacterial agent (Zhang et al., 2012), and novel anthraquinone [2-(dimethoxymethyl)-1-hydroxyanthracene-9,10-dione] which exhibited strong inhibitory activities against MRSA ATCC43300 and MRSA CGMCC 1.12409 (with MIC (minimum inhibitory concentration) values of 3.9 and $7.8 \mu \mathrm{g} / \mathrm{ml}$, respectively) and moderate activitzies against tested strains of Vibrio (with MIC values ranging from 15.6 to $62.5 \mu \mathrm{g} / \mathrm{ml}$ ) (Wang et al., 2018). This fungus can also be found in a plant, soil, marine habitat, and air (Ebada et al., 2018).

The macroscopic characterization showed that the isolate Dc08 colony was solid green with hairy surface and white-flat edges (Fig. 2). This fungus had round conidia, conidiophores, vesicles, phialide, and metula (Fig. 2). Molecular identification 


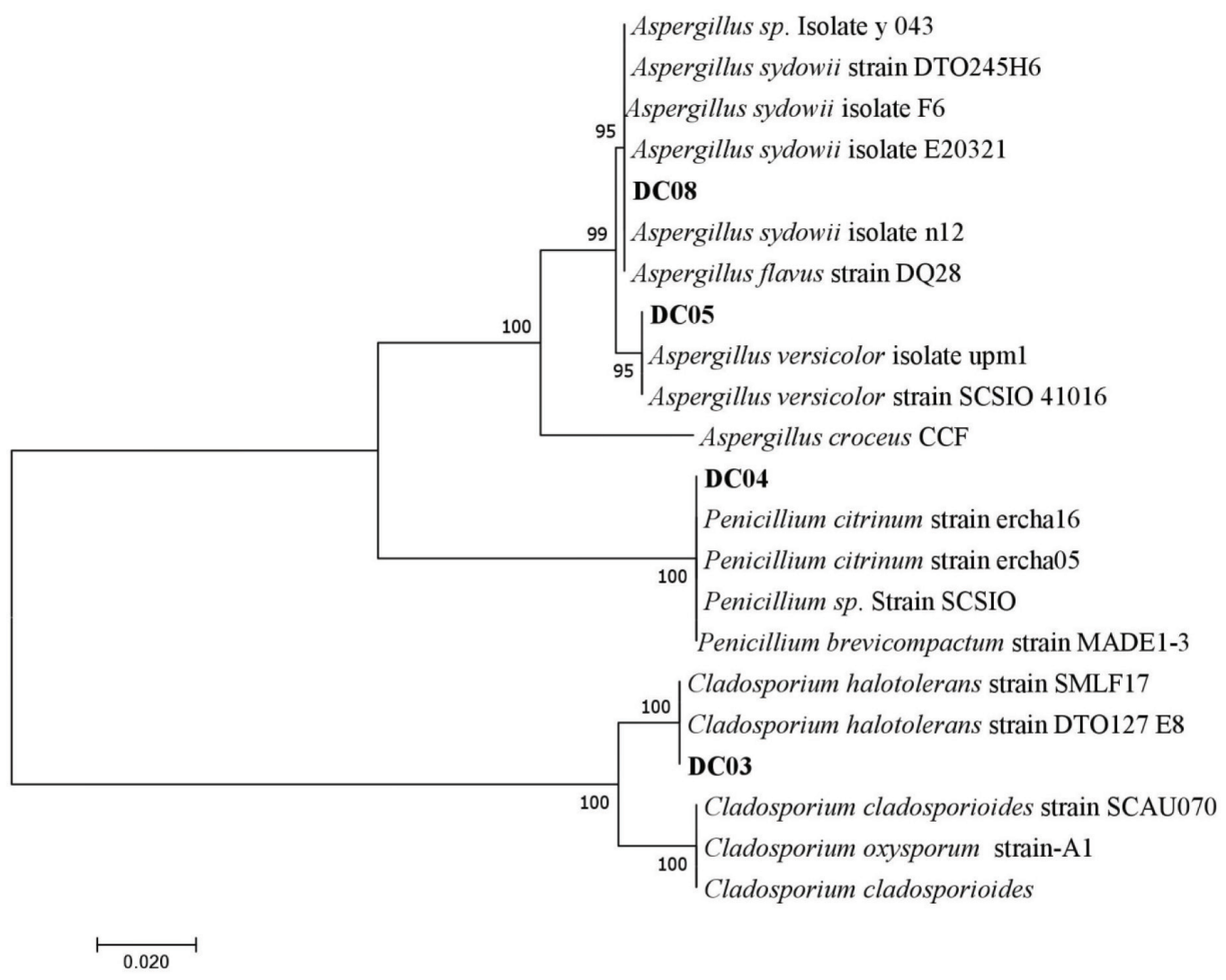

Figure 3. Neighbor-joining phylogenetic tree of potential fungal isolates from Dactylospongia sp.

showed that Dc08 had 100\% identity with Aspergillus sydowii strain E20321 ITS and identified as A. sydowii MN859970 (Fig. 3). Gao et al. (2017) reported about bioactive compounds from A. sydowii, a fungal strain obtained from the Marine Culture Collection of China. Lumichrome, N-acetyltyramine, 3-(2-hydroxypropyl)-4-(hexa-2E,4E-dien-6-yl)furan-2(5H)one, 1,4-dioxa-9,12-diazacyclohexadecane-5,8,13,16-tetraone, and cycloerodiol were succeed isolated from the EtOAc extract of this fungal and displayed moderate antibacterial activity with an MIC value between 6.3 and $25.0 \mu \mathrm{M}$.

The bioactivities of secondary metabolites from marine fungi reveal interesting pharmacological activities, and the fungi from the genera Penicillium and Aspergillus were the major object in this field. Most of the published work on secondary metabolites of marine fungi has focused on these genera due to the ability of these fungi to produce the new compounds (Imhoff, 2016).

\section{CONCLUSION}

Marine-derived fungi have already provided a variety of pharmacologically active novel secondary metabolites and thus represent a valuable resource for structurally unique and interesting biological properties. In this study, we had succeeded in the isolation of nine fungi-derived marine sponge Dactylospongia sp. and screened for their antimicrobial and cytotoxic activities. In further research, it is challenging to isolate the bioactive compounds from the potential marine-derived fungi, especially for P. citrinum Dc04 for the discovery of new drug candidates.

\section{ACKNOWLEDGMENT}

This work was financially supported by the Ministry of Research and Technology, Indonesia in the project "Master Program of Education Leading to Doctoral Degree for Excellent Graduate research". under Contract 163/SP2H/LT/DRPM/2019.

The authors would like to thank Dr. Nicole J. De Voogd from Natural Biodiversity Center, the Netherlands, for her kind assistance in the identification of the marine sponge.

\section{CONFLICT OF INTERESTS}

Authors declare that they do not have any conflicts of interest.

\section{REFERENCES}

Abraham EP, Loder PB. In: Flynn EH (ed.). Cephalosporins and penicillins; chemistry and biology. Academic Press, NewYork, NY, pp $1-26,1972$.

Amagata T, Amagata A, Tenney K, Valeriote FA, Lobkovsky E, Clardy J, Crews P. Unusual C25 steroids produced by a sponge-derived Penicillium citrinum. Org Lett, 2003; 5(23):4393-6.

Atashpaz S, Khani S, Barzegari A, Barar J, Vahed S, Azarbaijani $\mathrm{R}$, Omidi Y. A robust universal method for extraction of genomic DNA from bacterial species. Microbiology, 2010; 79(4):538-42.

Bao J, Sun YL, Zhang XY, Han Z, Gao HC, He F, Qian PY, Qi SH. Antifouling and antibacterial polyketides from marine gorgonian coral-associated fungus Penicillium sp. SCSGAF 0023. J Antibiot 2013, 66:219-23.

Binh NT, Lam PVH, Diep CN. Bioactive compounds from marine fungus Penicillium citrinum strain nd7c by gas chromatographymass spectrometry. Pharm Chem J, 2018; 5(1):211-24. 
Blunt JW, Copp BR, Hu W, Munro MHG, Northcote PT, Prinsep MR. Marine natural products. Nat Prod Rep, 2007; 24:31-86.

Blunt JW, Copp BR, Keyzers RA, Munro MHG, Prinsepn MR. Marine natural products. Nat Prod Rep, 2015; 32:116-211.

Davis WW, Stout TR. Disc plate method of microbiological antibiotic assay. J Microbiol, 1971; 22(4):659-65.

Ebada SS, El-Neketi M, Ebrahim W, Mándi A, Kurtán T, Kalscheuer R. Phytochemistry letters cytotoxic secondary metabolites from the endophytic fungus Aspergillus versicolor ku258497. Phytochem Lett, $2018 ; 24: 88-93$.

Ferrer C, Colom F, Frases S, Mulet E, Abad JL, Alió JL. Detection and identification of fungal pathogens by PCR and by ITS2 and 5.8S ribosomal DNA typing in ocular infections. J Clin Microb, 2001; 39(8):2873-9.

Gamal-Eldeen AM, Abdel-Lateff A, Okino, T. Modulation of carcinogen metabolizing enzymes by chromanone $\mathrm{A}$; a new chromone derivative from algicolous marine fungus Penicillium sp. Environ Toxicol Pharmacol, 2009; 28:317-22.

Gao T, Cao F, Yu H, Zhu H. Secondary metabolites from the marine fungus Aspergillus sydowii. Chem Nat Compd, 2017; 53(6).

Guo Z-Y, Tan M-H, Liu C-X, Lv M-M, Deng Z CF. Aspergoterpenins a-d: four new antimicrobial endophytic fungus Aspergillus versicolor. Molecules, 2018; 23(1291):1-10.

Handayani D, Ahdinur RF, Rustini R. Antimicrobial activity of endophytic fungi from marine sponge Haliclonafascigera. J App Pharm Sci, 2015a; 5(10):154-6.

Handayani D, Aminah I. Antibacterial and cytotoxic activities of ethyl acetate extract of symbiotic fungi from West Sumatra marine sponge Acanthrongylophoraingens. J App Pharm Sci, 2017a; 7(2):237-40.

Handayani D, Ananda N, Artasasta MA, Rustini R, Fadriyanti $\mathrm{O}$, Tallei TE. Antimicrobial activity screening of endophytic fungi extracts isolated from brown algae Padina sp. J App Pharm Sci, 2019a; 9(3):9-13.

Handayani D, Artasasta MA. Antibacterial and cytotoxic activities screening of symbiotic fungi extract isolated from marine sponge Neopetrosiachaliniformis AR-01. J App Pharm Sci, 2017b; 7(5):66-9.

Handayani D, Murniati M, Rustini R. In vitro inhibitory activity of ethyl acetate extract of symbiotic bacteria isolated from the marine sponge Haliclona fascigera against Multi-drug Resistant Organism (MDRO). J App Pharm Sci, 2016; 6(11):218-22.

Handayani D, Rasyid W, Rustini ZE, Hertiani T. Cytotoxic activity screening of fungal extracts derived from the West Sumatran marine sponge Haliclona fascigera to several human cell lines: Hela, WiDr, T47D, and Vero. JApp Pharm Sci, 2018a; 8(1):55-8.

Handayani D, Rivai H, Mulyana R, Suharti N, Rasyid R, Hertiani T. Antimicrobial and cytotoxic activities of endophytic fungi isolated from mangrove plant Sonneratia alba Sm. J App Pharm Sci, 2018b; 8(2):49-53.

Handayani D, Sandrawati N, Nestianda O, Ruslan R, Fajrina A, Tallei TE. Cytotoxic and antimicrobial activities of ethyl acetate extract of mangrove plant Scyphiphora hydrophyllacea C. F. Gaertn-Associated fungi. J Appl Pharm Sci, 2019b; 9(6):75-9.

Handayani D, Sandrawaty N, Murniati M, Regina R. Screening of endophytic bacteria isolated from marine sponge Haliclona fascigera for inhibition against clinical isolates of methicillin-resistant staphylococcus aureus (MRSA). J App Pharm Sci, 2015b; 5(9):139-42.
Hu Y, Chen J, Hu G, Yu J, Zhu X, Lin Y, Chen S, Yuan J. Statistical research on the bioactivity of new marine natural products discovered during the 28 years from 1985 to 2012. Mar Drugs, 2015; 13:202-21.

Imhoff JF. Natural products from marine fungi-still an underrepresented resource. Mar drugs, 2016; 14(16):19.

Kjer J, Debbab A, Aly AH, Proksch P. Methods for isolation of marine-derived endophytic fungi and their bioactive secondary products. Nat Protoc, 2010; 5(3):479-90.

Kumar S, Stecher G, Tamura K. MEGA7: molecular evolutionary genetics analysis version 7.0 for bigger datasets. Mol Biol Evol, 2016; 33(7):1870-4

Meyer BN, Ferrign RN, Putnam JE, Jacobson JE, Nicholas DE, McLaughlin JL, Brineshrimp: a convenient general bioassay for active plant constituents. Planta Med, 1982, 45:31-4.

Pang X, Lin X, Wang J, Liang R, Tian Y, Salendra L. Three new highly oxygenated sterols and one new dihydroisocoumarin from the marine sponge derived fungus Cladosporium sp. scsio41007. Steroids, 2017; 30(40):1-6

Sandrawati N, Pariatno R, Suharti N, Handayani D. In vitro cytotoxic activity assay of bacteria extract derived marine sponge Haliclona fascigera toward Hela, WiDr, T47D, and Vero cell line. J Appl Pharm Sci, 2019; 9(08):66-70.

Shao CL, Wang CY, Gu YC, Wei MY, Pan JH, Deng DS, She $\mathrm{ZG}$, Lin YC. Penicinoline, a new pyrrolyl4 quinolinone alkaloid with an unprecedented ring systemfromanendophyticfungus Penicilliumsp. Bioorg Med Chem Lett, 2010; 20:3284-6.

Song F, Ren B, Chen C, Yu K, Liu XZY. Three new sterigmatocystin analogues from marine-derived fungus Aspergillus versicolor mf359. Appl Microbiol Biotechnol, 2014; 98:3753-8.

Subramani R, Kumar R, Prasad P, Aalbersberg W. Cytotoxic and antibacterial substances against multi-drug resistant pathogens from marine sponge symbiont: citrinin, a secondary metabolite of Penicillium sp. Asian Pac J Trop Biomed, 2013; 3(4):291-6.

Tiwari P, Kumar B, Kaur M, Kaur G, Kaur H. Phytochemical screening and extraction : a review. Int Pharm Sci, 2011; 1(1):98-106.

Wang JF, Liu PP, Wang Y, Wang H, Li J, Zhuang YB, Zhu WM. Antimicrobial aromatic polyketides from gorgonian-associated fungus, Penicillium commune 518. Chin J Chem, 2012; 30:1236-42.

Wang W, Chen R, Luo Z, Wang WCJ. Antimicrobial activity and molecular docking studies of a novel anthraquinone from a marine- derived fungus Aspergillus versicolor.Nat. Prod Res, 2018; 6419(12):558-63.

Zhang Y, Li XM, Wang BG. Anthraquinone derivatives produced by marine-derived fungus Aspergillus versicolor EN-7. Biosci Biotechnol Biochem, 2012; 76:1774-6.

How to cite this article:

Sandrawati N, Hati SP, Yunita F, Putra AE, Ismed F, Tallei TE, Hertiani T, Handayani D. Antimicrobial and cytotoxic activities of marine sponge-derived fungal extracts isolated from Dactylospongia sp. J Appl Pharm Sci, 2020; 10(04): 028-033. 